\title{
Cumulative evidence for relationships between multiple variants of HNF1B and the risk of prostate and endometrial cancers
}

Yu Tong ${ }^{1,2}$, Yi Qu ${ }^{1,2}$, Shiping $\mathrm{Li}^{1,2}$, Fengyan Zhao ${ }^{1,2}$, Yibin Wang ${ }^{1,2^{*}}$ and Dezhi Mu ${ }^{1,2^{*}}$

\begin{abstract}
Background: To provide a synopsis of the current understanding of the association between variants of HNF1B and cancer susceptibility, we conducted a comprehensive research synopsis and meta-analysis to evaluate associations between HNF1B variants and prostate and endometrial cancers.

Results: Eighteen studies totaling 34,937 patients and 55,969 controls were eligible for this meta-analysis. Four variants showed a significant association with the risk of individual cancer. Strong significant associations were found between rs4430796 A and the risk of both prostate cancer $\left(O R=1.247, p=2.21 \times 10^{-77}\right)$ and endometrial cancer $\left(O R=1.217, p=8.98 \times 10^{-16}\right)$; the AA, AG genotypes also showed strong significant associations with the risk of prostate cancer $\left(O R 1=1.517, p=4.46 \times 10^{-22} ; O R 2=1.180, p=0.002\right)$. There was a strong significant association between rs7501939 $\mathrm{G}$ and the risk of prostate cancer $\left(O R=1.201, p=9.31 \times 10^{-31}\right)$. Strong significant association was found between $\mathrm{rs} 11649743 \mathrm{G}\left(\mathrm{OR}=1.138, p=1.08 \times 10^{-12}\right)$, rs3760511 C (OR=1.214, $\left.p=1.57 \times 10^{-19}\right)$ and the prostate cancer risk:the GG, AG genotypes of rs 11649743 also showed strong significant associations with the risk of prostate cancer $\left(O R 1=1.496, p=3.32 \times 10^{-6} ; O R 2=1.276, p=7.82 \times 10^{-6}\right)$. All the cumulative epidemiological evidence of associations was graded as strong.
\end{abstract}

Conclusions: Our study summarizes the evidence and helps to reveal that common variants of HNF1B are associated with risk of prostate and endometrial cancer.

Keywords: HNF1B, Variants, Prostate cancer, Endometrial cancer

\section{Background}

Human cancers result in Considerable morbidity and mortality. Family history, ethnicity, lifestyle and region are potential risk factors for cancer development [1-4]. However, family-based and adoption studies have provided major evidence for the role of genes in the development of cancers [5-7].

Owing to advances in sequencing technologies and genome-wide association studies (GWAS), a large number of genetic variants correlated with various cancers have been identified $[8,9]$. Multiple studies have examined the

\footnotetext{
* Correspondence: yibinwang666@163.com; mudz@scu.edu.cn

'Department of Pediatrics, West China Second University Hospital, Sichuan

University, No.17, Section 3, Renmin Nan Road, Chengdu 610041, Sichuan

Province, China

Full list of author information is available at the end of the article
}

relationship between the hepatocyte nuclear factor-1 beta (HNF1B, formerly known as TCF2) locus (on chromosome 17q12) and cancer risk [10-13]. HNF1B is a member of the homeodomain-containing superfamily of transcription factors and is involved in the tissue-specific regulation of many genes expressed in various organs [14] and during embryonic development [15]. Patients with a heterozygous $H N F 1 B$ deletion exhibit renal disease, elevated liver enzymes, and diabetes [16]. HNF1B is strongly associated with the risks of many cancers, including prostate cancer [10, 17],ovarian cancer [18-20],endometrial cancer [12, 21, 22] and lung cancer [13]. Recently, it has been reported that the rs7501939 single-nucleotide polymorphism (SNP) in HNF1B confers a poor overall survival in patients with multiple myeloma [23]. 
However, fine-mapping studies have revealed a complex genetic architecture of the HNF1B locus, demonstrating that variants of $H N F 1 B$ and the direction of their effects differ between cancer types. SNPs rs4430796 and rs7501939, are both associated with the prostate cancer risk across many ethnic groups [24]. The same SNPs, are also associated with endometrial cancer risk in women of European background [12]. Yet, the SNP rs757210, in high linkage disequilibrium with rs4430796, is the most strongly associated with serous epithelial ovarian cancer [18].

Here, we collected data related to the associations between $H N F 1 B$ variants and cancer phenotypes, and performed a comprehensive meta-analysis, involving a total of 34,937 patients and 55,969 controls, to derive more precise estimates of the associations between $H N F 1 B$ variants and susceptibility to prostate and endometrial cancers.

\section{Methods}

\section{Search strategy and inclusion criteria}

The US National Library of Medicine's PubMed, Embase, OMIM, ISI Web of Science, and Chinese National Knowledge Infrastructure (CNKI) databases were searched in a systematic manner to retrieve all genetic association studies of $H N F 1 B$ variants and cancers published before July 2017. The search strategy was based on a combination of the terms (Hepatocyte nuclear factor-1 beta or HNF1B) and (cancers or tumors). The references of all computer-identified publications were searched for additional studies, and the PubMed option "Related Articles" was also used to search for potentially relevant papers. Searches were performed by two independent reviewers (Yu Tong and Yibin Wang). The language of the publications did not influence article selections.

Studies were included if they met the following criteria. (1) the study reported original data from case-control or cohort studies, (2) the study reported alleles and genotypes for $H N F 1 B$ variants, and (3) the numbers of subjects possessing each allele and genotype in the cancer and control groups were available. No restrictions were set for the source of controls (general population, clinic, or hospital). Studies were excluded when: (i) they lacked sufficient information; (ii) they were published as letters to editors or conference abstracts; (iii) they were studies about cancer mortality.

\section{Data extraction}

Data were extracted independently by two investigators (Yu Tong and Yibin Wang), who used recommended guidelines for reporting on meta-analyses of observational studies. The following data were extracted from the eligible studies: authors, journal title, year of publication, country of origin, selection and characteristics of cases and controls, demographic data, ethnicity of the study population, numbers of eligible and genotyped cases and controls, and genotype distributions in cases, controls, and available subgroups. Furthermore, we examined whether genotype frequencies in control groups conformed to the Hardy-Weinberg equilibrium (HWE) was determined. Any disagreement was adjudicated by a third author (Yi Qu).

\section{Statistical analysis}

The odds ratio was used as the metric of choice for each study. To detect overall genetic associations, allele frequencies were computed for studies reporting allele and genotype data. Pooled odds ratios were computed by the fixed effects model and the random effects model based on heterogeneity estimates. Once an overall gene effect was confirmed, the genetic effects and mode of inheritance were estimated using the genetic model-free approach suggested by Minelli et al. We performed Cochran's Q test and calculated $I^{2}$ statistic to evaluate heterogeneity between studies. Harbord's test was performed to evaluate publication bias. Potential small-study bias was evaluated by Egger's test [25]. Sensitivity analyses were conducted to examine if the significant association would be lost when the first published report was excluded, or studies deviated from HWE in controls were excluded. All analyses were conducted using Stata, version 14.0 (StataCorp, 2017), with the metan, metabias, metacum, and metareg commands.

Venice criteria [26] were applied to evaluate the epidemiological credibility of significant associations identified by meta-analysis. Credibility was defined in three categories: amount of evidence (graded by the sum of test alleles or genotypes among cases and controls: A for $>1000$, B for 100-1000, and C for < 100), replication of the association (graded by the heterogeneity statistic: A for $I^{2}<25 \%$, B for $I^{2}$ between 25 and 50\%, and C for $I^{2}>$ $50 \%$ ), and protection from bias (graded as A: there was no observable bias, and bias was unlikely to explain the presence of the association, B: bias could be present, C: bias was evident or was likely to explain the presence of the association, association. $\mathrm{C}$ was also assigned to an association with a summary OR less than 1.15, unless the association had been replicated by GWAS or GWAS meta-analysis from collaborative studies. With no evidence of publication bias). Cumulative epidemiological evidence for significant associations was thought to be strong if all three grades were $\mathrm{A}$, moderate if all three grades were $\mathrm{A}$ or $\mathrm{B}$, and weak if any grade was $\mathrm{C}$.

To determine whether a significant association could be excluded as a false positive finding, FPRP (false positive report probability) was calculated using the method described by Wacholder et al. [27]. FPRP $<0.05$, 
$0.05 \leq$ FPRP $\leq 0.20$, and FPRP $>0.20$ were considered strong, moderate, and weak evidence of true association, respectively.

\section{Results}

\section{Eligible studies}

Our initial database search identified 113 potentially relevant studies. Based on a review of titles and abstracts, 55 articles were retained. The full text of these 55 articles was reviewed in detail, and 18 studies containing 36 datasets were eligible for inclusion in the meta-analysis. The specific process for identifying eligible studies and inclusion and exclusion criteria are summarized in Fig. 1a.

Characteristics of the included articles are presented in Allelic associations: 1 . Of the 36 datasets, 26 were on prostate cancer $[10,24,28-41]$; and10 were on endometrial cancer [42, 43]. All eligible studies had case-control designs. Cases were recruited from hospital patients and controls were mainly healthy individuals recruited from the hospital or community and were unrelated to cases.

\section{Allelic associations}

HNF1B variants and the risk of prostate cancer

rs4430796 $\mathrm{G}>\mathrm{A}$ and the risk of prostate cancer All 15 publications were included in the evaluation of the association between the HNF1B rs4430796 and prostate cancer (Allelic associations: 1). A strong significant association with risk of prostate cancer was observed $\left(p=2.21 \times 10^{-77}\right.$, fixed effect $O R=1.247,95 \% C I: 1.218,1.276 ; Q=21.98, p=0.637$,
$I^{2}=0.0 \%$, Fig. 2). Sensitivity analyses in Asians $(p=8.32 \times$ $10^{-8}$, fixed effect $O R=1.369,95 \% C I: 1.221,1.536 ; Q=2.13$, $\left.p=0.712, I^{2}=0.0 \%\right)$ and Caucasians $\left(p=1.21 \times 10^{-69}\right.$, fixed effect $O R=1.241,95 \% C I: 1.212,1.271 ; Q=17.09, p=0.517$, $I^{2}=0.0 \%$ ) demonstrated a pattern similar to that of the full population. However, this effect was weak in the Africans $(p=0.002$, fixed effect $O R=1.275,95 \% C I: 1.093,1.487$; $\left.Q=0.08, p=0.777, I^{2}=0.0 \%\right)$. No publication bias was found in the eligible studies (Harbord's test $p=0.253$ ).

rs7501939 $\mathrm{A}>\mathrm{G}$ and the risk of prostate cancer Six publications were included in the evaluation of the association between the HNF1B rs7501939 and prostate cancer (Table 1). A strong significant association with risk of prostate cancer was observed $\left(p=9.31 \times 10^{-31}\right.$, fixed effect $O R=1.201,95 \% C I: 1.164,1.239 ; Q=8.24$, $p=0.510, I^{2}=0.0 \%$, Fig. 2b). Sensitivity analyses in Caucasians demonstrated a pattern similar to that of the full population $\left(p=1.04 \times 10^{-29}\right.$, fixed effect $O R=$ 1.203, 95\% CI: 1.165, 1.242; $Q=5.04, p=0.539, I^{2}=$ $0.0 \%)$. No publication bias was found in the eligible studies (Harbord's test $p=0.864$ ).

rs11649743 $A>G$ and the risk of prostate cancer Two publications included data regarding the association between the HNF1B rs11649743 and prostate cancer (Table 1). There was a significant difference in the between-study heterogeneity among the eligible studies $\left(Q=15.1, p=0.035, I^{2}=53.6 \%\right)$. Strong significant association was observed with the prostate cancer risk ( $p=$ $1.08 \times 10^{-12}$, random effect $O R=1.138,95 \% C I: 1.062$,
Potential relevant studies identified and screened for retrieval $(\mathrm{N}=113)$

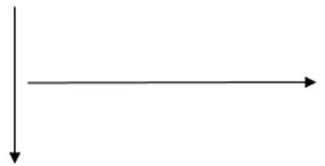

Studies have possible association $(\mathrm{N}=54)$

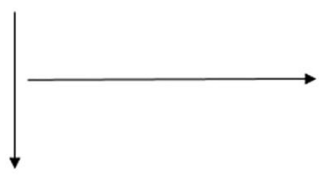

Studies included in this meta-analysis for HNFB1 variants and human prostate and endometria cancers (N=18)
Not related to the association between HNFB1 variants and cancers risk based on the title and abstracts $(\mathrm{N}=59)$

\begin{tabular}{ll}
\hline Studies excluded $(\mathrm{N}=36)$ : \\
Review articles & $(\mathrm{N}=6)$ \\
Patients only & $(\mathrm{N}=13)$ \\
No data & $(\mathrm{N}=15)$ \\
Tissue samples & $(\mathrm{N}=2)$
\end{tabular}

Fig. 1 Flow diagram of included and excluded studies 
Table 1 Characteristics of case-control studies included in a meta-analysis of the association between HNF1B variants and human cancers

\begin{tabular}{|c|c|c|c|c|c|c|c|}
\hline Ref & Cancer & Region/Center & Ethnicity & $\begin{array}{l}\text { rs4430796 cases/ } \\
\text { controls }\end{array}$ & $\begin{array}{l}\text { rs7501939 cases/ } \\
\text { controls }\end{array}$ & $\begin{array}{l}\text { rs11649743 cases/ } \\
\text { controls }\end{array}$ & $\begin{array}{l}\text { rs3760511 cases/ } \\
\text { controls }\end{array}$ \\
\hline [31] & prostate & China & Asian & 195/160 & & & \\
\hline [32] & prostate & Korean & Asian & $240 / 223$ & $240 / 223$ & & $240 / 223$ \\
\hline [24] & prostate & USA Europe & Caucasian & $10,272 / 9123$ & $10,247 / 9100$ & $10,272 / 9123$ & $10,272 / 9123$ \\
\hline [10] & prostate & CAPS & Caucasian & 2874/1708 & & 2852/1688 & \\
\hline [10] & prostate & $\mathrm{JHH}$ & Caucasian & $1521 / 479$ & & $1490 / 470$ & \\
\hline [10] & prostate & ATBC & Caucasian & $901 / 902$ & & $927 / 921$ & \\
\hline [10] & prostate & FPCC & Caucasian & $620 / 618$ & & $656 / 656$ & \\
\hline [10] & prostate & HPFS & Caucasian & $581 / 591$ & & $596 / 611$ & \\
\hline [10] & prostate & PLCO & Caucasian & $1121 / 1048$ & & 1166/1093 & \\
\hline [10] & prostate & ACS & Caucasian & $1716 / 1718$ & & $1759 / 1775$ & \\
\hline$[28]^{\mathrm{a}}$ & prostate & Iceland & Caucasian & $1501 / 11289$ & $1501 / 11289$ & & \\
\hline$[28]$ & prostate & Netherlands & Caucasian & $997 / 1464$ & $997 / 1464$ & & \\
\hline [28] & prostate & Spain & Caucasian & $456 / 1078$ & $456 / 1078$ & & \\
\hline$[28]$ & prostate & USA & Caucasian & $536 / 514$ & $536 / 514$ & & \\
\hline [29] & prostate & USA & Caucasian & $542 / 473$ & $542 / 473$ & & \\
\hline [30] & prostate & USA & Caucasian & $1563 / 576$ & $1563 / 576$ & & $1563 / 576$ \\
\hline [30] & prostate & USA & African & $364 / 353$ & $364 / 353$ & & $364 / 353$ \\
\hline$[36]$ & prostate & Japan & Asian & $311 / 1035$ & & & \\
\hline$[40]$ & prostate & USA & African & $454 / 301$ & $454 / 301$ & & \\
\hline$[37]$ & prostate & China & Asian & $105 / 78$ & & & \\
\hline$[38]$ & prostate & Japan & Asian & $518 / 323$ & & & \\
\hline$[31]$ & prostate & USA & Caucasian & $754 / 2713$ & & & \\
\hline$[31]$ & prostate & CGEM & Caucasian & 1176/1101 & & & \\
\hline$[39]$ & prostate & Singapore & Asian & 289/141 & & & \\
\hline$[32]$ & prostate & USA & Caucasian & $166 / 33$ & & & \\
\hline [41] & prostate & USA & Caucasian & $759 / 790$ & & & \\
\hline$[42]^{a}$ & endometrial & MEC & Caucasian & $106 / 813$ & $106 / 813$ & & \\
\hline$[42]$ & endometrial & $\mathrm{WHI}$ & Caucasian & $868 / 3037$ & $868 / 3037$ & & \\
\hline$[42]$ & endometrial & MEC & African & $68 / 820$ & $68 / 820$ & & \\
\hline$[42]$ & endometrial & WHI & African & $35 / 350$ & $35 / 350$ & & \\
\hline$[42]$ & endometrial & MEC & Asian & $121 / 1204$ & $121 / 1204$ & & \\
\hline$[42]$ & endometrial & $\mathrm{WHI}$ & Asian & $8 / 161$ & $8 / 161$ & & \\
\hline [42] & endometrial & MEC & Latino & $104 / 673$ & $104 / 673$ & & \\
\hline$[42]$ & endometrial & WHI & Latino & $20 / 207$ & $20 / 207$ & & \\
\hline$[42]$ & endometrial & MEC & Hawaiian & $27 / 344$ & $27 / 344$ & & \\
\hline [43] & endometrial & Australia and the UK & Caucasian & $3048 / 9528$ & $3048 / 9528$ & & \\
\hline Total & & & & $34,937 / 55969$ & $21,305 / 42508$ & 19,718/16337 & $12,439 / 10275$ \\
\hline
\end{tabular}

CAPS = CAncer Prostate in Sweden;JHH = The Johns Hopkins Hospital study ATBC $=$ Beta-Carotene Cancer Prevention Study;FPCC $=$ CeRePP French Prostate CaseControl Study;HPFS = The Health Professionals Follow-up Study;PLCO = Prostate, Lung, Colon and Ovarian (PLCO) Cancer Screening Trial; MEC = Multiethnic Cohort Study; WHI = Women's Health Initiative; CGEM = Cancer Genetic Markers of Susceptibility Study

${ }^{a}$ Genome-wide association study (GWAS) 


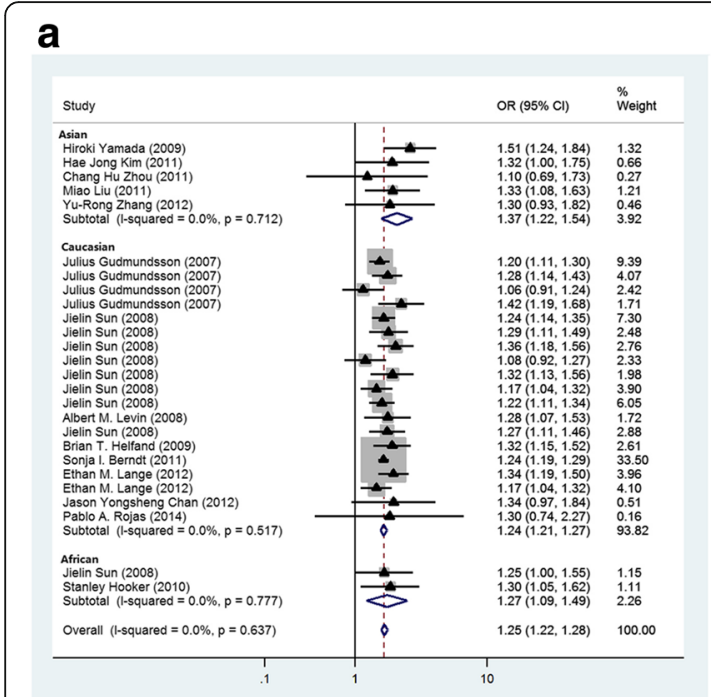

b

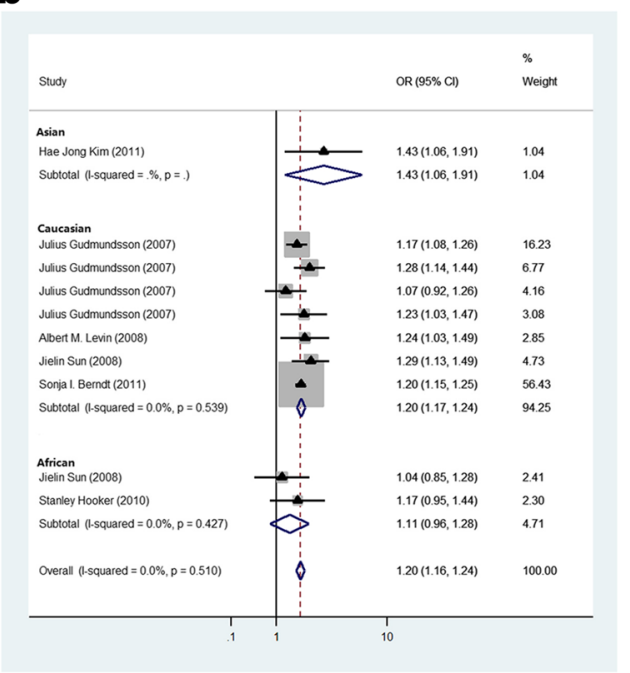

C

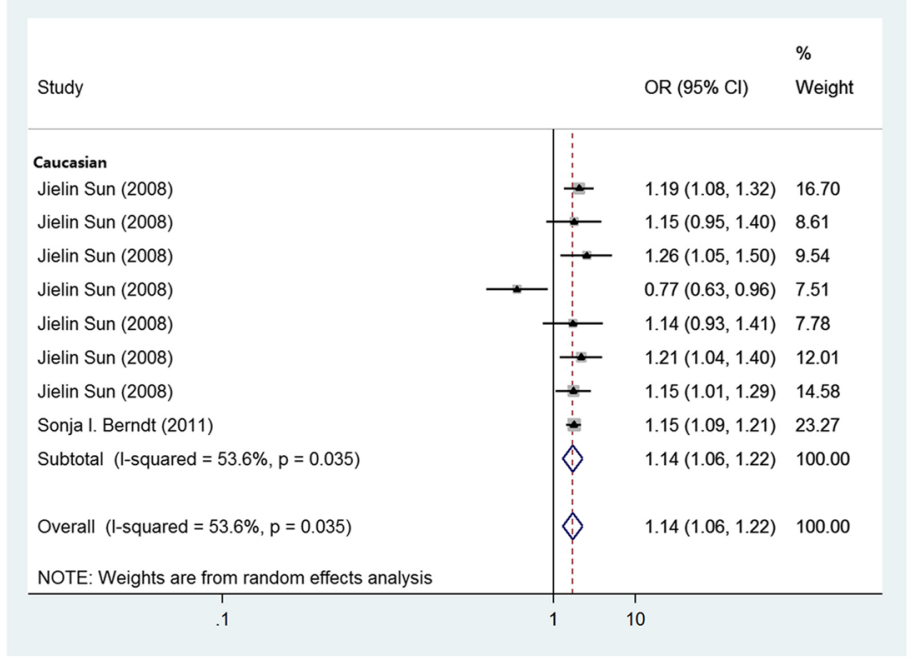

d

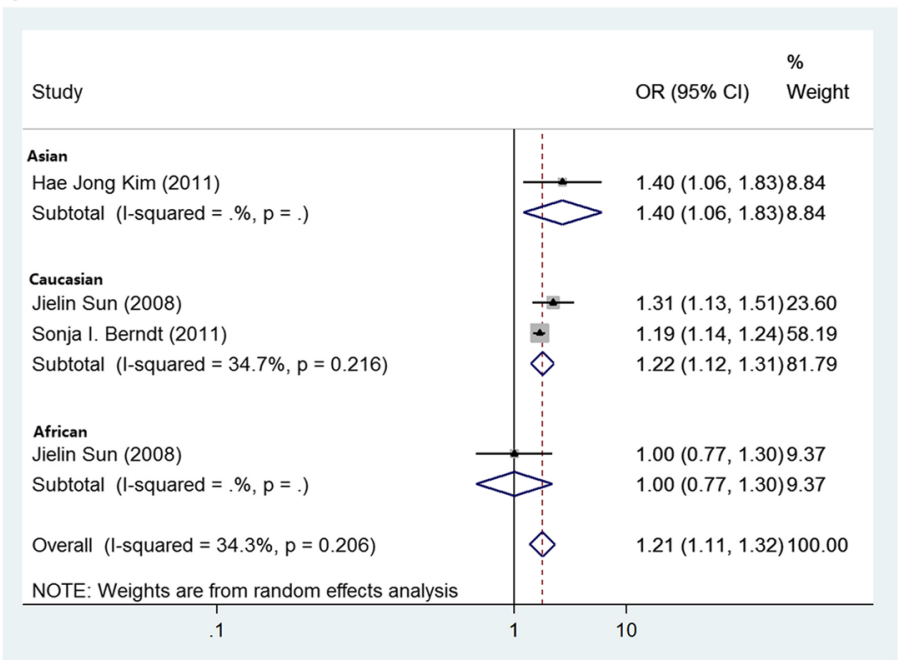

Fig. 2 a Fixed-effects meta-analysis of allele (A versus G) of the HNF1B rs4430796 G > A and prostate cancer. The OR of each study is represented by a square, and the size of the square represents the weight of each study with respect to the overall estimate. $95 \%$ Cls are represented by the horizontal lines, and the diamond represents the overall estimate and its $95 \% \mathrm{Cl}$. b. Fixed-effects meta-analysis of allele (G versus $A$ ) of the HNF1B gene rs7501939 A > G and prostate cancer. c. Radom-effects meta-analysis of allele (G versus A) of the HNF1B gene rs11649743 A> G and prostate cancer. $\mathbf{d}$. Fixed-effects meta-analysis of allele (C versus A) of the HNF1B gene rs3760511 A >C and prostate cancer

1.219, Fig. 2c). No publication bias was found in the eligible studies (Harbord's test $p=0.588$ ).

rs3760511 $\mathrm{A}>\mathrm{C}$ and the risk of prostate cancer Three publications were included in the evaluation of the association between the HNF1B rs3760511 and prostate cancer. There was a strong significant association between rs3760511 and the risk of prostate cancer, and moderate heterogeneity was found among the eligible studies $\left(p=1.57 \times 10^{-19}\right.$, random effect $O R=1.214,95 \%$ $C I:$ 1.113, 1.325; $Q=4.57, p=0.206, I^{2}=34.3 \%$, Fig. $2 \mathrm{~d}$ ). Sensitivity analyses in Caucasians demonstrated a pattern similar to that of the full population $\left(p=6.11 \times 10^{-19}\right.$, random effect $O R=1.216,95 \% C I: 1.125,1.314 ; Q=1.53$, $\left.p=0.216, I^{2}=34.7 \%\right)$. No publication bias was found in the eligible studies (Harbord's test $p=0.778$ ).

\section{HNF1B variants and the risk of endometrial cancer rs4430796 $G>A$ and the risk of endometrial cancer}

Two publications were included in the evaluation of the association between the HNF1B rs4430796 A>G and endometrial cancer (Table 1). There was a strong significant association between rs4430796 and the endometrial cancer risk $\left(p=8.98 \times 10^{-16}\right.$, fixed effect $O R=1.217,95 \%$ CI: 1.160, 1.276; $Q=5.72, p=0.768, I^{2}=0.0 \%$, Fig. 3). Similar patterns were found in the Caucasians $(p=3.73 \times$ $10^{-14}$, fixed effect $O R=1.215,95 \% C I: 1.155,1.277 ; Q=$ $0.57, p=0.751, I^{2}=0.0 \%$ ). Lack of significant association 


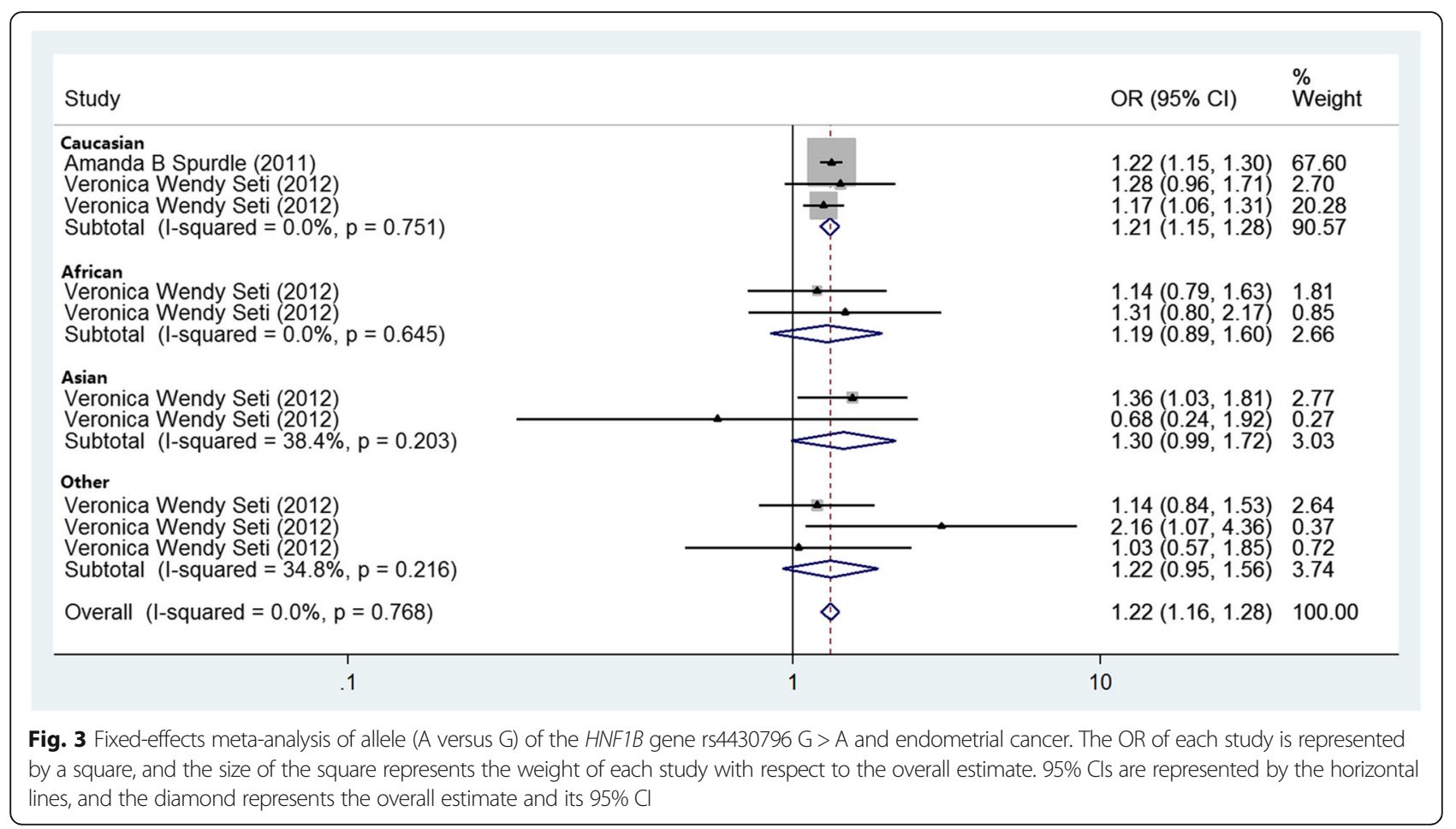

was found in Africans $(p=0.235$, fixed effect $O R=1.193$, 95\% CI: 0.891, 1.597; $Q=0.21, p=0.645, I^{2}=0.0 \%$ ), the Asians $(p=0.058$,fixed effect $O R=1.304,95 \% C I$ : 0.992 , 1.716; $Q=1.62, p=0.203, I^{2}=38.4 \%$ ), and Latino and Hawaiian $(p=0.122$, fixed effect $O R=1.217,95 \% C I$ : $0.949,1.562 ; Q=3.07, p=0.216, I^{2}=34.8 \%$ ). No publication bias was found in the eligible studies (Harbord's test $p=0.950)$.

\section{rs7501939 $\mathrm{G}>\mathrm{A}$ and the risk of endometrial cancer}

Two publications were included in the analysis of the association between the HNF1B rs7501939 and endometrial cancer (Table 1). Although the risk of endometrial cancer was increased in individuals carrying the $\mathrm{G}$ allele, compared to those with the A allele, lack of significant association was found with endometrial cancer risk $(p=0.258$, random effect $O R=1.204,95 \% C I: 0.873,1.660$ ). The same pattern was observed in Caucasians $(p=0.751$, random effect $O R=1.104$, 95\% CI: 0.599, 2.036; $Q=190.13, p=0.000, I^{2}=98.9 \%$ ), Africans $(p=0.122$, random effect $O R=1.254,95 \% C I$ : $\left.0.942,1.670 ; Q=0.93, p=0.336, I^{2}=0.0 \%\right)$, Asians $(p=$ 0.918 , random effect $O R=1.040,95 \% C I: 0.492,2.196$; $Q=2.23, p=0.136, I^{2}=55.1 \%$ ) and Latino and Hawaiian $(p=0.262$, random effect $O R=1.389,95 \% C I: 0.783$, 2.464; $Q=6.28, p=0.043, I^{2}=68.2 \%$ ) (Data not shown).

\section{Genotype comparison}

\section{rs4430796 $G>A$ and the risk of prostate cancer}

Of the 15 publications, only seven reported genotype information. The genotype distribution of the HNF1B rs4430796 among case and control groups is presented in Table 2. The genotype effects for AA versus GG $(O R 1)$ and AG versus GG (OR2) were calculated for each study. A multivariate meta-analysis was conducted to estimate the pooled risk. There was a significantly increased risk of prostate cancer among individuals with the homozygous AA genotype $\left(p=4.46 \times 10^{-22}\right.$, fixed effect $O R 1=1.517,95 \% C I$ : 1.394, 1.651; $Q=12.27, p=$ $\left.0.424, I^{2}=2.2 \%\right)$ and heterozygous AG genotype $(p=$ 0.002, random effect $O R 2=1.180,95 \%$ CI: 1.064, 1.309; $\left.Q=17.50, p=0.132, I^{2}=31.4 \%\right)$. The pooled estimates were similar to those obtained after removal of the study with HW disequilibrium [10], i.e., fixed effect $O R 1=1.524$ $\left(p=7.97 \times 10^{-18}, 95 \%\right.$ CI: 1.384, 1.677; $Q=12.23, p=0.347$, $\left.I^{2}=10.1 \%\right)$ and random effect $O R 2=1.198(p=0.003,95 \%$ CI: $\left.1.064,1.348 ; Q=16.43, p=0.126, I^{2}=33.1 \%\right)$.

\section{rs11649743 A > G and the risk of prostate cancer}

Only one publication reported genotype information for rs11649743. However, this publication included relevant data for different populations and regions. The genotype distribution for the HNF1B rs11649743 among case and control groups is presented in Table 3 . The genotype effects for GG versus AA (OR1) and GA versus AA $(O R 2)$ were calculated for each study. Multivariate meta-analysis was conducted to estimate the pooled risk. There was a significantly increased risk of prostate cancer among individuals with the homozygous GG genotype $\left(p=3.32 \times 10^{-6}\right.$, fixed effect $O R 1=1.496,95 \% C I$ : $1.262,1.772)$ and heterozygous AG genotype $(p=7.82 \times$ 
Table 2 The association between the HNF1B rs4430796 and prostate cancer (genotype distribution of case-control studies included in a meta-analysis)

\begin{tabular}{|c|c|c|c|c|c|c|c|c|c|}
\hline \multirow[t]{2}{*}{ Ref } & \multicolumn{3}{|c|}{ Cases } & \multicolumn{3}{|c|}{ Controls } & \multirow[t]{2}{*}{ HWE } & \multirow{2}{*}{$\begin{array}{l}\text { AA vs GG } \\
\text { OR1 }(95 \% \mathrm{Cl})\end{array}$} & \multirow{2}{*}{$\begin{array}{l}\text { AG vs GG } \\
\text { OR2 (95\% Cl) }\end{array}$} \\
\hline & GG & $A G$ & AA & GG & $A G$ & $\mathrm{AA}$ & & & \\
\hline [31] & 16 & 60 & 119 & 77 & 73 & 10 & 0.889 & $1.494(1.249-1.786)$ & $1.087(0.920-1.285)$ \\
\hline [10] & 446 & 1355 & 1073 & 316 & 883 & 509 & ${ }^{\mathrm{a}} 0.025$ & $1.697(1.255-2.296)$ & $1.285(0.984-1.679)$ \\
\hline [10] & 254 & 779 & 488 & 106 & 253 & 120 & 0.155 & $1.955(1.441-2.653)$ & $1.433(1.060-1.937)$ \\
\hline [10] & 87 & 395 & 419 & 136 & 431 & 335 & 0.445 & $1.190(0.869-1.631)$ & $1.077(0.820-1.415)$ \\
\hline [10] & 149 & 308 & 163 & 161 & 309 & 148 & 0.495 & $1.756(1.264-2.441)$ & $1.304(0.974-1.746)$ \\
\hline [10] & 113 & 289 & 179 & 153 & 300 & 138 & 0.349 & $1.332(1.052-1.688)$ & $0.998(0.808-1.233)$ \\
\hline [10] & 254 & 522 & 345 & 257 & 529 & 262 & 0.378 & $1.445(1.196-1.747)$ & $1.206(1.018-1.428)$ \\
\hline [10] & 357 & 843 & 516 & 434 & 850 & 434 & 0.332 & $1.806(1.351-2.413)$ & $1.543(1.187-2.006)$ \\
\hline [37] & 12 & 34 & 59 & 6 & 34 & 38 & 0.335 & $0.776(0.269-2.244)$ & $0.500(0.168-1.486)$ \\
\hline [38] & 52 & 214 & 252 & 45 & 149 & 129 & 0.425 & $1.691(1.076-2.656)$ & $1.243(0.792-1.950)$ \\
\hline [39] & 21 & 99 & 169 & 11 & 63 & 67 & 0.235 & $0.966(0.417-2.238)$ & $0.514(0.217-1.215)$ \\
\hline [32] & 11 & 75 & 80 & 4 & 15 & 14 & 0.498 & $1.321(0.604-2.889)$ & $0.823(0.372-1.823)$ \\
\hline [41] & 240 & 390 & 129 & 198 & 388 & 204 & 0.310 & 2.078(0.579-7.455) & $1.818(0.510-6.484)$ \\
\hline Pooled & & & & & & & & $1.517(1.394-1.651)$ & $1.180(1.064-1.309)$ \\
\hline
\end{tabular}

$\mathrm{HWE}=p$-value for Hardy-Weinberg equilibrium;

${ }^{\mathrm{a}}$ Hardy-Weinberg disequilibrium was observed in the control group

$10^{-6}$, fixed effect $\left.O R 2=1.276,95 \% C I: 1.072,1.519\right)$. No between-study heterogeneity was found for the homozygous GG genotype $\left(Q=2.19, p=0.902, I^{2}=0.0 \%\right)$ or for the heterozygous GA genotype ( $\left.Q=2.30, p=0.891, I^{2}=0.0 \%\right)$.

\section{Cumulative evidence of association}

\section{Epidemiological credibility of significant associations}

Venice criteria were applied to evaluate these significant associations. Details of protection from bias for genetic variants significantly associated with prostate and endometrial cancer risk in meta-analyses are shown in Table 4. Grades of A were given to all these meta-analyses for amount of evidence, replication of association, and protection from bias. Therefore, strong evidence of true association with cancer risk is assigned to rs4430796, rs7501939, rs11649743, and rs3760511 for prostate cancer and rs4430796 for endometrial cancer.

\section{Probability of true association with cancer risk}

To evaluate the probability of true association with cancer risk for the nominally significant variants, FPRP value was calculated. All associations with cancer risk had a FPRP value $<0.001$. Thus, all the cumulative epidemiological evidence of associations was graded as strong.

\section{Discussion}

To our knowledge, this is the first general overview of the association between $H N F 1 B$ variants and susceptibility to prostate and endometrial cancers. Our primary analysis revealed that, rs4430796 A, showed strong

Table 3 Association between the HNF1B rs11649743 and prostate cancer (genotype distribution of case-control studies included in the meta-analysis)

\begin{tabular}{|c|c|c|c|c|c|c|c|c|c|}
\hline \multirow[t]{2}{*}{ Ref } & \multicolumn{3}{|c|}{ Cases } & \multicolumn{3}{|c|}{ Controls } & \multirow[t]{2}{*}{ HWE } & \multirow{2}{*}{$\begin{array}{l}\text { GG vs AA } \\
\text { OR1 }(95 \% \text { Cl) }\end{array}$} & \multirow{2}{*}{$\begin{array}{l}\text { GA vs AA } \\
\text { OR2 }(95 \% \mathrm{Cl})\end{array}$} \\
\hline & $\overline{\mathrm{AA}}$ & GA & GG & $\overline{\mathrm{AA}}$ & GA & GG & & & \\
\hline [10] & 115 & 895 & 1842 & 90 & 587 & 1009 & 0.292 & $1.460(1.099-1.941)$ & $1.220(0.910-1.635)$ \\
\hline [10] & 40 & 395 & 1055 & 14 & 139 & 317 & 0.396 & $1.165(0.626-2.168)$ & $0.995(0.525-1.884)$ \\
\hline$[10]$ & 18 & 219 & 690 & 27 & 250 & 644 & 0.324 & $1.607(0.877-2.946)$ & $1.314(0.704-2.451)$ \\
\hline$[10]$ & 20 & 191 & 445 & 32 & 211 & 413 & 0.227 & $1.724(0.971-3.062)$ & $1.448(0.801-2.618)$ \\
\hline$[10]$ & 19 & 159 & 418 & 27 & 174 & 410 & 0.063 & $1.449(0.793-2.646)$ & $1.299(0.695-2.426)$ \\
\hline$[10]$ & 28 & 361 & 777 & 47 & 359 & 687 & 0.200 & $1.898(1.176-3.065)$ & $1.688(1.034-2.756)$ \\
\hline$[10]$ & 48 & 495 & 1216 & 62 & 546 & 1167 & 0.425 & $1.346(0.916-1.979)$ & $1.171(0.788-1.740)$ \\
\hline Pooled & & & & & & & & $1.496(1.262-1.772)$ & $1.276(1.072-1.519)$ \\
\hline
\end{tabular}




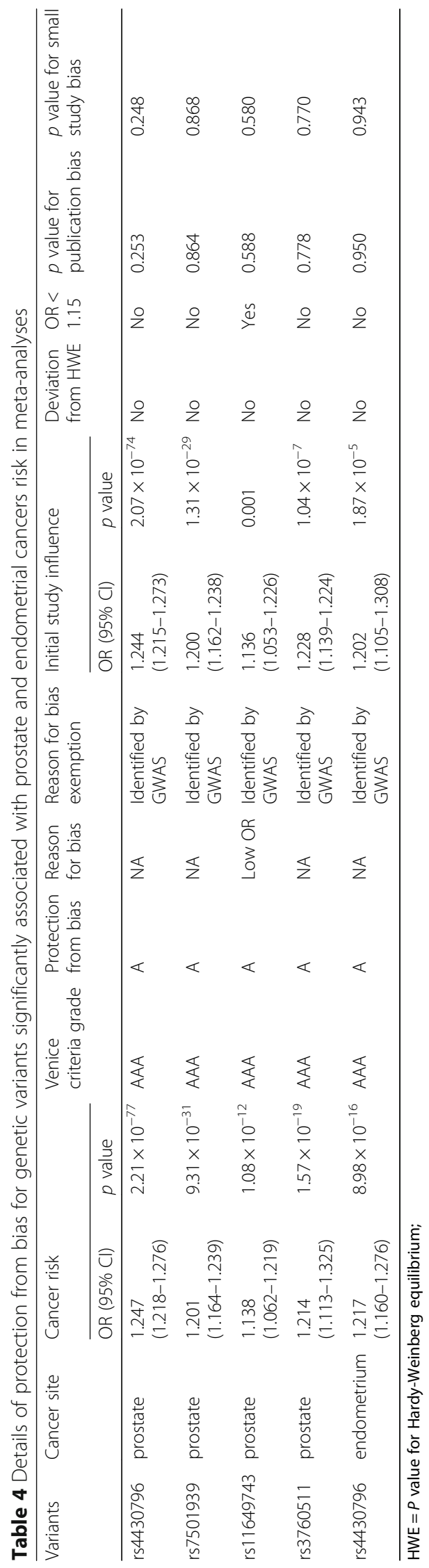


significant associations with risk of both prostate cancer $\left(O R=1.247, p=2.21 \times 10^{-77}\right.$, ) and endometrial cancer $\left(O R=1.217, p=8.98 \times 10^{-16}\right)$; the AA, AG genotypes also showed strong significant associations with risk of prostate cancer $\left(O R 1=1.517, p=4.46 \times 10^{-22} ; \quad O R 2=\right.$ $1.180, p=0.002$ ). Sensitivity analyses in Caucasians demonstrated patterns similar to that of the full population. However, lack of significant association was found in Africans, which is likely due to the considerably smaller sample size. There was a strong significant association between rs7501939 A and the risk of prostate cancer $\left(O R=1.201, p=9.31 \times 10^{-31}\right)$; however, lack of significant association with endometrial cancer risk was observed $(O R=1.104, p=0.751$. For rs11649743 G, strong significant association was found with the prostate cancer risk $\left(O R=1.138, p=1.08 \times 10^{-12}\right)$, and the GG, AG genotypes also showed strong significant associations with the risk of prostate cancer $(O R 1=1.496, p=$ $3.32 \times 10^{-6} ;$ OR2 $=1.276, p=7.82 \times 10^{-6}$ ). Strong significant association was also found between rs3760511 C and the risk of prostate cancer $(O R=1.214, p=1.57 \times$ $10^{-19}$ ). Using the Venice criteria and false-positive report probability tests, we graded all the cumulative evidence of significant associations with prostate and endometrial cancers risk as strong.

Our findings were based on several gene-association studies, including several thousand participants, and were robust in terms of study design and sensitivity analyses. We found no evidence of publication bias or small study bias based on funnel plots. Between-study heterogeneity was found in allelic association studies ( $G$ versus A) of rs7501939, and in allelic (G versus A) of rs11649743 for prostate cancer. When HWE was examined, one study showed deviation. Our results were robust to the removal of this study.

$H N F 1 B$ encodes three isoforms: isoforms (A, B and C); isoform $A$ and $B$ act as transcriptional activators and isoform $\mathrm{C}$ acts as a transcriptional repressor [44]. HNF1B is involved in the regulation of cell proliferation, and genetic variation in $H N F 1 B$ might modulate the risk of cancer [45]. However, the precise pathomechanism by which the genetic variation affects susceptibility to cancers is still unclear. In a recent GWAS, rs4430796 and rs7501939 in HNF1B were associated with the risks of both endometrial cancer in women of European background [43] and prostate cancer [28]. Several studies examined the associations between HNF1B and prostate cancer and endometrial cancer across various populations [12, 46, 47]. According to these studies, the two variants are associated with the risks of prostate cancer and endometrial cancer. Moreover, the rs4430796 G allele is significantly associated with an increased risk of lung cancer [13] . In 2013, Pharoah et al. identified that the $H N F 1 B$ rs757210 is specific to serous epithelial ovarian cancer by pooling data from GWAS and follow-up genotyping; the analysis included 43 studies from the Ovarian Cancer Association Consortium [18]. At the same time, Shen et al. found evidence for a differential effect of HNF1B on the serious and clear cell subtypes of ovarian cancer. They found that HNF1B loss-of-function role and gain-of-function are related to serous and clear cell ovarian cancers, respectively [20]. Another research discovered HNF1B rs7501939 was a susceptibility locus for testicular germ cell tumor [48]. Taken together, these studies suggest that specific $H N F 1 B$ variants predispose individuals to clear cell ovarian, endometrial, lung and prostate cancers, et al.

There are several limitations of the study. First, it is likely that some publications were overlooked although we conducted an exhaustive literature search, some relevant published studies with null results were not identified. Second, due to insufficient data, we were unable to evaluate publication bias for associations between several variants in $8 \mathrm{q} 24$ region and prostate and endometrial cancer. Third, a unified analysis standard across studies could not be defined for lack of raw data from the original publications. Therefore, future studies with larger sample size are warranted to confirm these associations.

\section{Conclusions}

Given the relevance of $H N F 1 B$ variants to cancer biology, we attempted to estimate the strength of the genetic associations between these variants and prostate and endometrial cancers. This Human Genome Epidemiology (HuGE) systematic review presents strong evidence for an association between $H N F 1 B$ variants and prostate and endometrial cancers, both overall and in Caucasians, Asians, Africans, and Indians, suggesting a multiplicative genetic model for variants of $H N F 1 B$ among different ethnic populations. Our study results also suggest that $H N F 1 B$ plays an important role in prostate and endometrial cancers, and these variations may serve as efficient and economical biomarkers for the diagnosis of prostate and endometrial cancers.

\begin{abstract}
Abbreviations
CNKI: Chinese National Knowledge Infrastructure; GWAS: genome-wide association studies; HNF1B: hepatocyte nuclear factor-1 beta; SNP: singlenucleotide polymorphism
\end{abstract}

\section{Acknowledgments}

We are grateful to Editage Company for help in revising this paper.

\section{Funding}

Data collection, design and analysis of the study was supported by National Natural Science Foundation of China: 81401238, 81330016, 81630038; Grants from the Ministry of Education of China: 313037, 20110181130002; Grant from State Commission of Science Technology of China: 2012BAI04B04. Grants from the Science and Technology Bureau of Sichuan province: 2012SZ0010, 2014SZ0149, 2016JY0028; Grant from the clinical discipline program (Neonatology) from the Ministry of Health of China: 1311200003303. 


\section{Availability of data and materials}

The datasets used and/or analyzed during the current study are available from the corresponding author on reasonable request.

\section{Authors' contributions}

Data were extracted independently by $\mathrm{YT}$ and $\mathrm{YW}, \mathrm{YT}, \mathrm{SL}, \mathrm{FZ}$ and DM contributed to writing the manuscript. Data with any disagreement was adjudicated by YQ. All authors were responsible for drafting the manuscript, read and approved the final version.

\section{Ethics approval and consent to participate}

This study has not directly involved humans, though is based on retrospectively analyzed pre-existing data.

\section{Consent for publication}

Not applicable.

\section{Competing interests}

The authors declare that they have no competing interests.

\section{Publisher's Note}

Springer Nature remains neutral with regard to jurisdictional claims in published maps and institutional affiliations.

\section{Author details}

'Department of Pediatrics, West China Second University Hospital, Sichuan University, No.17, Section 3, Renmin Nan Road, Chengdu 610041, Sichuan Province, China. ${ }^{2}$ Key Laboratory of Obstetric \& Gynecologic and Pediatric Diseases and Birth Defects of Ministry of Education, West China Second University Hospital, Sichuan University, No.17, Section 3, Renmin Nan Road, Chengdu 610041, Sichuan Province, China.

Received: 26 April 2018 Accepted: 3 July 2018

Published online: 27 July 2018

\section{References}

1. Nam RK, Toi A, Klotz LH, Trachtenberg J, Jewett MA, Appu S, Loblaw DA, Sugar L, Narod SA, Kattan MW. Assessing individual risk for prostate cancer. J clin oncol offic j Am Soc Clin Oncol. 2007;25(24):3582-8.

2. Soliman PT, Broaddus RR, Schmeler KM, Daniels MS, Gonzalez D, Slomovitz BM, Gershenson DM, Lu KH. Women with synchronous primary cancers of the endometrium and ovary: do they have lynch syndrome? I clin oncol offic j Am Soc Clin Oncol. 2005;23(36):9344-50.

3. Pfeiffer RM, Park Y, Kreimer AR, Lacey JV Jr, Pee D, Greenlee RT, Buys SS, Hollenbeck A, Rosner B, Gail MH, et al. Risk prediction for breast, endometrial, and ovarian cancer in white women aged $50 \mathrm{y}$ or older: derivation and validation from population-based cohort studies. PLoS Med. 2013;10(7): e1001492.

4. So HC, Kwan JS, Cherny SS, Sham PC. Risk prediction of complex diseases from family history and known susceptibility loci, with applications for cancer screening. Am J Hum Genet. 2011;88(5):548-65.

5. Ivanovich J, Babb S, Goodfellow P, Mutch D, Herzog T, Rader J, Whelan A. Evaluation of the family history collection process and the accuracy of cancer reporting among a series of women with endometrial cancer. Clin can res offic j Am Assoc Cancer Res. 2002;8(6):1849-56.

6. Samimi G, Bernardini MQ, Brody LC, Caga-Anan CF, Campbell IG, ChenevixTrench G, Couch FJ, Dean M, de Hullu JA, Domchek SM, et al. Traceback: a proposed framework to increase identification and genetic counseling of BRCA1 and BRCA2 mutation carriers through family-based outreach. J clin oncol offic j Am Soc Clin Oncol. 2017;35(20):2329-37.

7. Rebbeck TR. Prostate Cancer genetics: variation by race, ethnicity, and geography. Semin Radiat Oncol. 2017;27(1):3-10.

8. Kuchenbaecker KB, McGuffog L, Barrowdale D, Lee A, Soucy P, Dennis J, Domchek SM, Robson M, Spurdle AB, Ramus SJ, et al. Evaluation of polygenic risk scores for breast and ovarian Cancer risk prediction in BRCA1 and BRCA2 mutation carriers. J Natl Cancer Inst. 2017;109(7):djw302.

9. Mhatre S, Wang Z, Nagrani R, Badwe R, Chiplunkar S, Mittal B, Yadav S, Zhang $\mathrm{H}$, Chung $\mathrm{CC}$, Patil $\mathrm{P}$, et al. Common genetic variation and risk of gallbladder cancer in India: a case-control genome-wide association study. Lancet Oncol. 2017;18(4):535-44.
10. Sun J, Zheng SL, Wiklund F, Isaacs SD, Purcell LD, Gao Z, Hsu FC, Kim ST, Liu W, Zhu Y, et al. Evidence for two independent prostate cancer riskassociated loci in the HNF1B gene at 17q12. Nat Genet. 2008;40(10):1153-5.

11. Stevens VL, Ahn J, Sun J, Jacobs EJ, Moore SC, Patel AV, Berndt SI, Albanes D, Hayes RB. HNF1B and JAZF1 genes, diabetes, and prostate cancer risk. Prostate. 2010;70(6):601-7.

12. Painter JN, O'Mara TA, Batra J, Cheng T, Lose FA, Dennis J, Michailidou K, Tyrer JP, Ahmed S, Ferguson K, et al. Fine-mapping of the HNF1B multicancer locus identifies candidate variants that mediate endometrial cancer risk. Hum Mol Genet. 2015;24(5):1478-92.

13. Sun JZ, Yang XX, Hu NY, Li X, Li FX, Li M. Genetic variants in MMP9 and TCF2 contribute to susceptibility to lung Cancer. Chinese j cancer res Chung-kuo yen cheng yen chiu. 2011;23(3):183-7.

14. Massa F, Garbay S, Bouvier R, Sugitani Y, Noda T, Gubler MC, Heidet L, Pontoglio M, Fischer E. Hepatocyte nuclear factor 1 beta controls nephron tubular development. Development. 2013;140(4):886-96.

15. Heliot C, Desgrange A, Buisson I, Prunskaite-Hyyrylainen R, Shan J, Vainio S, Umbhauer M, Cereghini S. HNF1B controls proximal-intermediate nephron segment identity in vertebrates by regulating notch signalling components and Irx1/2. Development. 2013;140(4):873-85.

16. Raile K, Klopocki E, Holder M, Wessel T, Galler A, Deiss D, Muller D, Riebel T, Horn D, Maringa $M$, et al. Expanded clinical spectrum in hepatocyte nuclear factor 1b-maturity-onset diabetes of the young. J Clin Endocrinol Metab. 2009;94(7):2658-64.

17. Thomas G, Jacobs KB, Yeager M, Kraft P, Wacholder S, Orr N, Yu K, Chatterjee N, Welch R, Hutchinson A, et al. Multiple loci identified in a genome-wide association study of prostate cancer. Nat Genet. 2008; 40(3):310-5.

18. Pharoah PD, Tsai YY, Ramus SJ, Phelan CM, Goode EL, Lawrenson K, Buckley M, Fridley BL, Tyrer JP, Shen H, et al. GWAS meta-analysis and replication identifies three new susceptibility loci for ovarian cancer. Nat Genet. 2013; 45(4):362-70. 370e361-362

19. Burghaus S, Fasching PA, Haberle L, Rubner M, Buchner K, Blum S, Engel A, Ekici $A B$, Hartmann $A$, Hein $A$, et al. Genetic risk factors for ovarian cancer and their role for endometriosis risk. Gynecol Oncol. 2017;145(1):142-7.

20. Shen H, Fridley BL, Song H, Lawrenson K, Cunningham JM, Ramus SJ, Cicek MS, Tyrer J, Stram D, Larson MC, et al. Epigenetic analysis leads to identification of HNF1B as a subtype-specific susceptibility gene for ovarian cancer. Nat Commun. 2013;4:1628.

21. Mandato VD, Farnetti E, Torricelli F, Abrate M, Casali B, Ciarlini G, Pirillo D, Gelli MC, Nicoli D, Grassi M, et al. HNF1B polymorphism influences the prognosis of endometrial cancer patients: a cohort study. BMC Cancer. 2015;15:229.

22. De Vivo I, Prescott J, Setiawan WW, Olson SH, Wentzensen N, Australian National Endometrial Cancer Study G, Attia J, Black A, Brinton L, Chen C, et al. Genome-wide association study of endometrial cancer in E2C2. Hum Genet. 2014;133(2):211-24

23. Rios-Tamayo R, Lupianez CB, Campa D, Hielscher T, Weinhold N, MartinezLopez J, Jerez A, Landi S, Jamroziak K, Dumontet C, et al. A common variant within the HNF1B gene is associated with overall survival of multiple myeloma patients: results from the IMMEnSE consortium and meta-analysis. Oncotarget. 2016;7(37):59029-48.

24. Berndt SI, Sampson J, Yeager M, Jacobs KB, Wang Z, Hutchinson A, Chung C, Orr N, Wacholder S, Chatterjee N, et al. Large-scale fine mapping of the HNF1B locus and prostate cancer risk. Hum Mol Genet. 2011;20(16):3322-9.

25. Egger M, Davey Smith G, Schneider M, Minder C. Bias in meta-analysis detected by a simple, graphical test. Bmj. 1997;315(7109):629-34.

26. Ioannidis JP, Boffetta P, Little J, O'Brien TR, Uitterlinden AG, Vineis P, Balding DJ, Chokkalingam A, Dolan SM, Flanders WD, et al. Assessment of cumulative evidence on genetic associations: interim guidelines. Int J Epidemiol. 2008;37(1):120-32

27. Wacholder S, Chanock S, Garcia-Closas M, El Ghormli L, Rothman N. Assessing the probability that a positive report is false: an approach for molecular epidemiology studies. J Natl Cancer Inst. 2004;96(6):434-42.

28. Gudmundsson J, Sulem P, Steinthorsdottir V, Bergthorsson JT, Thorleifsson G, Manolescu A, Rafnar T, Gudbjartsson D, Agnarsson BA, Baker A, et al. Two variants on chromosome 17 confer prostate cancer risk, and the one in TCF2 protects against type 2 diabetes. Nat Genet. 2007:39(8):977-83.

29. Levin AM, Machiela MJ, Zuhlke KA, Ray AM, Cooney KA, Douglas JA. Chromosome 17q12 variants contribute to risk of early-onset prostate cancer. Cancer Res. 2008;68(16):6492-5. 
30. Sun J, Purcell L, Gao Z, Isaacs SD, Wiley KE, Hsu FC, Liu W, Duggan D, Carpten JD, Gronberg H, et al. Association between sequence variants at $17 q 12$ and $17 q 24.3$ and prostate cancer risk in European and African Americans. Prostate. 2008;68(7):691-7.

31. Lange EM, Salinas CA, Zuhlke KA, Ray AM, Wang Y, Lu Y, Ho LA, Luo J, Cooney KA. Early onset prostate cancer has a significant genetic component. Prostate. 2012;72(2):147-56.

32. Rojas PA, Torres-Estay V, Cerda-Infante J, Montecinos VP, Dominguez J, Arenas J, Godoy AS, San Francisco IF. Association of a single-nucleotide polymorphism from chromosome 17q12 with the aggressiveness of prostate cancer in a Hispanic population. J Cancer Res Clin Oncol. 2014; 140(5):783-8.

33. Helfand BT, Loeb S, Meeks JJ, Fought AJ, Kan D, Catalona WJ. Pathological outcomes associated with the 17q prostate cancer risk variants. J Urol. 2009; 181(6):2502-7.

34. Zhang YR, Xu Y, Yang K, Liu M, Wei D, Zhang YG, Shi XH, Wang JY, Yang $F$, Wang $X$, et al. Association of six susceptibility loci with prostate cancer in northern chinese men. Asian Pacific j cancer preventAPJCP. 2012:13(12):6273-6.

35. Kim HJ, Bae JS, Lee J, Chang IH, Kim KD, Shin HD, Han JH, Lee SY, Kim W, Myung SC. HNF1B polymorphism associated with development of prostate cancer in Korean patients. Urology. 2011;78(4):969. e961-966

36. Yamada H, Penney KL, Takahashi H, Katoh T, Yamano Y, Yamakado M, Kimura T, Kuruma H, Kamata $\mathrm{Y}$, Egawa $\mathrm{S}$, et al. Replication of prostate cancer risk loci in a Japanese case-control association study. J Natl Cancer Inst. 2009;101(19):1330-6.

37. Zhou CH, Wang JY, Cao SY, Shi XH, Zhang YG, Liu M, Wang X, Huang $J$, Yang YG, Wei $D$, et al. Association between single nucleotide polymorphisms on chromosome $17 \mathrm{q}$ and the risk of prostate cancer in a Chinese population. Chinese j cancer. 2011;30(10):721-30.

38. Liu M, Suzuki M, Arai T, Sawabe M, Enomoto Y, Nishimatsu H, Kume H, Homma Y, Kitamura T. A replication study examining three common singlenucleotide polymorphisms and the risk of prostate cancer in a Japanese population. Prostate. 2011;71(10):1023-32.

39. Chan JY, Li H, Singh O, Mahajan A, Ramasamy S, Subramaniyan K, Kanesvaran R, Sim HG, Chong TW, Teo YY, et al. 8q24 and 17q prostate cancer susceptibility loci in a multiethnic Asian cohort. Urol Oncol. 2013;31(8):1553-60.

40. Hooker S, Hernandez W, Chen H, Robbins C, Torres JB, Ahaghotu C, Carpten J, Kittles RA. Replication of prostate cancer risk loci on 8q24, 11q13, 17q12, 19q33, and Xp11 in African Americans. Prostate. 2010;70(3):270-5.

41. Helfand BT, Fought AJ, Loeb S, Meeks JJ, Kan D, Catalona WJ. Genetic prostate cancer risk assessment: common variants in 9 genomic regions are associated with cumulative risk. J Urol. 2010;184(2):501-5.

42. Setiawan WW, Haessler J, Schumacher F, Cote ML, Deelman E, Fesinmeyer MD, Henderson BE, Jackson RD, Vockler JS, Wilkens LR, et al. HNF1B and endometrial cancer risk: results from the PAGE study. PLoS One. 2012;7(1):e30390.

43. Spurdle AB, Thompson DJ, Ahmed S, Ferguson K, Healey CS, O'Mara T, Walker LC, Montgomery SB, Dermitzakis ET, Australian National Endometrial Cancer Study G, et al. Genome-wide association study identifies a common variant associated with risk of endometrial cancer. Nat Genet. 2011;43(5):451-4.

44. Hajarnis SS, Patel V, Aboudehen K, Attanasio M, Cobo-Stark P, Pontoglio M, Igarashi P. Transcription factor hepatocyte nuclear factor-1 beta (HNF-1 beta) regulates MicroRNA-200 expression through a long noncoding RNA. J Biol Chem. 2015;290(41):24793-805.

45. Nemejcova K, Ticha I, Kleiblova P, Bartu M, Cibula D, Jirsova K, Dundr P. Expression, Epigenetic and Genetic changes of HNF1B in endometrial lesions. Pathol oncol res POR. 2016;22(3):523-30.

46. Grisanzio C, Werner L, Takeda D, Awoyemi BC, Pomerantz MM, Yamada $H$, Sooriakumaran P, Robinson BD, Leung R, Schinzel AC, et al. Genetic and functional analyses implicate the NUDT11, HNF1B, and SLC22A3 genes in prostate cancer pathogenesis. Proc Natl Acad Sci U S A. 2012;109(28):11252-7.

47. Waters KM, Le Marchand L, Kolonel LN, Monroe KR, Stram DO, Henderson BE, Haiman CA. Generalizability of associations from prostate cancer genome-wide association studies in multiple populations. Cancer epidemiol, biomarkers prevention public Am Assoc Cancer Res cosponsored Am Soc Preventive Oncol. 2009;18(4):1285-9.

48. Kristiansen W, Karlsson R, Rounge TB, Whitington T, Andreassen BK, Magnusson PK, Fossa SD, Adami HO, Turnbull C, Haugen TB, et al. Two new loci and gene sets related to sex determination and cancer progression are associated with susceptibility to testicular germ cell tumor. Hum Mol Genet. 2015;24(14):4138-46.

Ready to submit your research? Choose BMC and benefit from:

- fast, convenient online submission

- thorough peer review by experienced researchers in your field

- rapid publication on acceptance

- support for research data, including large and complex data types

- gold Open Access which fosters wider collaboration and increased citations

- maximum visibility for your research: over $100 \mathrm{M}$ website views per year

At BMC, research is always in progress.

Learn more biomedcentral.com/submissions 